\title{
Development and Validation of Novel UV Spectrophotometric Method for the Determination of Evogliptin Tartarate in Pharmaceutical Dosage Form
}

\author{
Yogesh Purushottam Agrawal*, Mona Yogesh Agrawal, Siddhesh Bharat Jadhav, Renuka Jagannath \\ Shinde
}

Department of Pharmaceutical Analysis, Government College of Pharmacy, Ratnagiri, University of Mumbai, Mumbai, Maharashtra, INDIA.

\begin{abstract}
Aim: Development of a novel precise, selective and sensitive UV spectrophotometric method for the estimation of Evogliptin tartarate in bulk and tablet dosage forms. Materials and Methods: The estimation was carried out using deionized water as solvent and Quantitation was achieved using double beam UV spectrophotometer at $267 \mathrm{~nm}$. Results: The Calibration curves of Evogliptin tartarate shows good linearity over the concentration range from $10-100 \mu \mathrm{g} / \mathrm{mL}$ with excellent correlation coefficient $\left(R^{2}=0.992\right)$. The percent relative standard deviation $<2.0 \%$ confirmed the precision of the method. Excellent recovery (98.86 to 99.51 ) with low percent relative error proved the accuracy of method. The specificity of the methods was analyzed by evaluating marketed pharmaceutical formulation of Evogliptin tartarate. Conclusion: In the present work we report for the first time, a UV-spectrophotometric method for the analysis of Evogliptin tartarate and the proposed method showed excellent sensitivity, selectivity and linearity as per ICH Q2 (R1) guidelines. In addition the effectiveness of the developed method was demonstrated with marketed pharmaceutical formulation reflects good recovery percentage. It is evident that the proposed method will serve as a standard protocol for routine analysis of Evogliptin tartarate in bulks, Pharmaceutical formulations and would be of great help to Pharmaceutical industries in the future.
\end{abstract}

Key words: Evogliptin tartarate, UV-Spectrophotometry, Pharmaceutical formulations, Analytical Method Development, Validation.

\section{INTRODUCTION}

Type 2 diabetes which is also referred to as non-insulin-dependent diabetes, accounts for more than $90 \%$ of patients with diabetes. ${ }^{1}$ The treatment guidelines for management of type 2 diabetes recommend addition of second-line agents like DPP-4 inhibitors to metformin (first line agents) for patients with insufficient control of hyperglycemia., ${ }^{2,3}$ Evogliptin tartarate (DA-1229) (Figure 1) is chemically (3R)-4-[(3R)-3 amino-4-(2,4,5triflurophenyl) butanoyl]-3-[(tert-butoxy) metbyl] piperazin-2-one piperazin tartarate, a novel oral DPP-4 inhibitor, was recently developed by Dong-A ST for treatment of type 2 diabetes improve glycemic control mainly via stimulation of glucose-mediated incretin secretion, resulting in increased insulin secretion and decreased glucagon release. ${ }^{4}$ These glucose-dependent mechanisms of DPP-4 inhibitor suggests a lower risk for hypoglycemia and positively affect metabolic abnormalities such as obesity, hypertension and dyslipidemia, which are associated with type 2 diabetes. ${ }^{5}$

In patients with type 2 diabetes mellitus, once-daily administration of Evogliptin $5 \mathrm{mg}$ for 12 weeks showed significant glucoselowering effects while in healthy volunteers, a single administration of Evogliptin showed a long half-life ( $\geq 30 \mathrm{hrs}$ ) and the pharmacokinetics of Evogliptin was not affected by food. ${ }^{6}$ Multiple-dosing studies signify that, 5-20 mg dose of Evogliptin exhibited linear pharmacokinetics and the
Submission Date: 23-07-2020; Revision Date: 08-09-2020; Accepted Date: 30-10-2020

DOI: 10.5530/ijper.54.4.214 Correspondence: Dr. Yogesh P Agrawal Assistant Professor, Government College of Pharmacy, Near Thiba Palace, Ratnagiri-415612, Maharashtra, INDIA.

Phone no: +919423720983 Email id: yogeshpagrawal@ yahoo.co.in

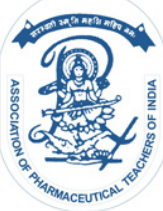

www.ijper.org 


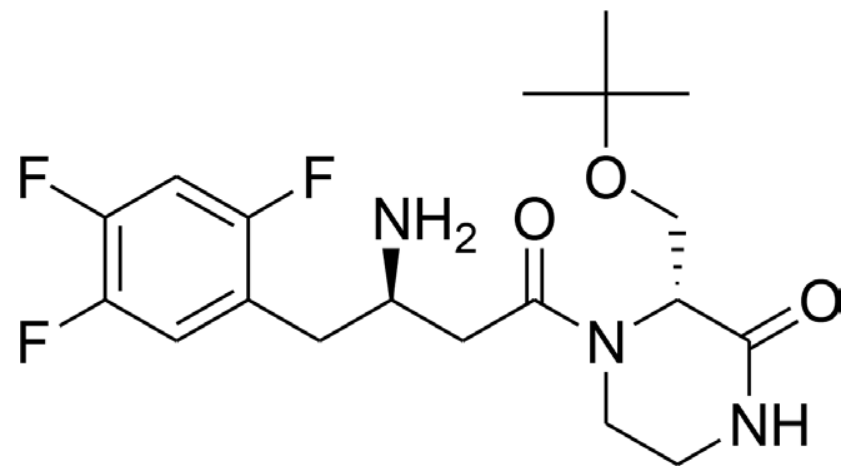

Figure 1: Molecular Structure of Evogliptin.

inhibitory effect on DPP-4 activity was sustained over 24 hrs. $^{7-9}$

Literaturesurveyreveals thatonlyLiquidChromatography with tandem $\mathrm{MS}^{10}$ or Orbitrap MS methods were reported for the determination of Evogliptin in plasma, urine $^{11}$ and liver of humans. ${ }^{12}$ Although these techniques have significant scientific merits such as good sensitivity and low detection limits, but they require long treatment procedures by the qualified operator with high cost implications. Alternatively, no assay procedure has been reported for the determination of this drug in bulk and its Pharmaceutical formulations. Spectrophotometry continues to be very popular amongst the various methods available for the determination of drugs, because of their simplicity, specificity and low cost. In recent advancement, electrochemical procedures offers imperative advantages, such as simplicity with cost effectiveness, rapid response, selectivity and high sensitivity $^{13,14}$ in the detection of analyte in various sample matrices and can be utilized for determination of Evogliptin in future. In present study, for the first time, a simple new spectrophotometric method for quantification of Evogliptin tartarate has been developed and validated according to the International Conference on Harmonization (ICH) guidelines ${ }^{15}$ and successfully applied for assay of Pharmaceutical formulations.

\section{MATERIALS AND METHODS Instrumentation}

A Shimadzu UV-visible spectrophotometer (Model UV-1800, Shimadzu Corporation, Spectrophotometric Division, Kyoto, Japan) with $10 \mathrm{~mm}$ quartz cuvettes were used to record the UV absorption spectra. Absorption of solutions was measured at medium speed with a sampling interval of $0.1 \mathrm{~nm}$. The instrument has a fixed slit width of $1 \mathrm{~nm}$. Shimadzu high precision analytical balance (Model AUX-220, Shimadzu Corporation,
Kyoto, Japan) was utilized for weighting. Deionised water prepared by Extrapure-10 water purification system (Lablink Corporation Pvt. Ltd., Mumbai, India) was used throughout the experiments.

\section{Chemicals and Reagents}

Pharmaceutical grade Evogliptin (API) in the form of Evogliptin tartarate powder was procured as gift sample from Alkem Laboratory Limited, Mumbai, India. Market Formulation Valera (containing $5 \mathrm{mg}$ Evogliptin Tartarate) used for method verification which was purchased from Indian local market. All chemicals and reagents were of analytical grade.

\section{Preparation of Standard}

\section{Evogliptin Standard solution stock $(1 \mathrm{mg} / \mathrm{mL})$}

Weighed and transferred $50 \mathrm{mg}$ of Evogliptin Tartarate into a $50 \mathrm{~mL}$ flask and made up to volume with deionised water. Further, the working standard solutions were prepared by diluting stock solutions with deionised water.

\section{Tablet test sample Preparation}

Weighed 20 tablets and crushed to fine powder. Accurately weighed Powder equivalent of $50 \mathrm{mg}$ of Evogliptin Tartarate to a $50 \mathrm{ml}$ volumetric flask to that added $10 \mathrm{ml}$ of methanol vortex for $5 \mathrm{~min}$ to dissolve, further added $30 \mathrm{~mL}$ of water and sonicate for $10 \mathrm{~min}$ with vigorous shaking. Allow to equilibrate at room temperature and diluted upto $50 \mathrm{~mL}$ with water. Centrifuged at 5000 RPM for 5 min. and filtered the supernatant solution through Whatman's filter paper No. 41 and first few $\mathrm{ml}$ was rejected. Use filtered solution as sample stock solution of Evogliptin Tartarate $(1 \mathrm{mg} / \mathrm{mL})$ for assay analysis.

\section{Procedure for construction of calibration curve}

Required amount of working standard solutions of Evogliptin Tartarate were transferred into the $10 \mathrm{~mL}$ volumetric flasks to get ten solutions in the concentration range of $10-100 \mu \mathrm{g} / \mathrm{mL}$. All these solutions were scanned in the range of 200-400 $\mathrm{nm}$ against deionised water as blank in spectrum mode and observed the maximum absorbance at wavelength $267 \mathrm{~nm}\left(\lambda_{\max }\right)$ for Evogliptin Tartarate (Figure 2). Further, the calibration curves were created by plotting a graph between peak amplitude against corresponding concentrations. In addition, regression equations were figured.

\section{Procedure for assay of sample solutions}

The sample solution was prepared by accurately transferring $2 \mathrm{~mL}$ sample stock solution into $10 \mathrm{~mL}$ 


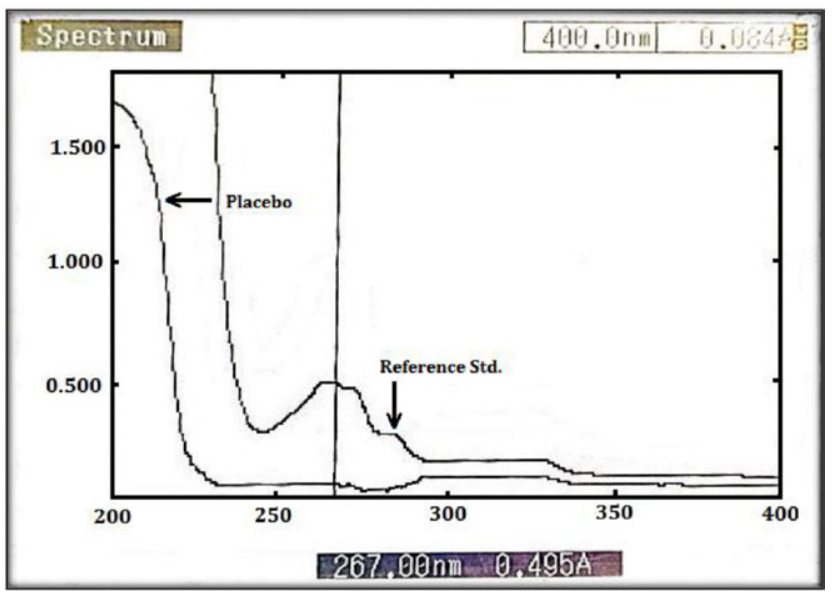

Figure 2: UV-spectra of Reference sample and Placebo in deionized water.

volumetric flask and the final volume was made with deionised water. Further, this solution was diluted with water to get the amount of Evogliptin in the range of calibration curve. The sample solution was scanned in the range of $200 \mathrm{~nm}-400 \mathrm{~nm}$ and concentration of Evogliptin was determined from the calibration curves of developed method.

\section{Stability study of solution}

Samples prepared for repeatability study were preserved for $24 \mathrm{hr}$ at room temperature and analyzed on the subsequent day to test for short-term stability. The $\%$ RSD was determined and found to be less than $2.0 \%$ which shows that stability of the solution at bench top.

\section{Specificity in the presence of excipient}

The established method was evaluated for the specificity using placebo. The over laid UV absorption spectra of placebo, blank and drug was compared in order to verify that none of the component interfered with the quantification of the drug (Figure 2).

\section{Intra-day (repeatability) and inter-day (intermediate) precision study}

Repeatability and intermediate precision of newly developed method was analyzed using the sample stock solution $(1 \mathrm{mg} / \mathrm{ml})$. Three different aliquots were diluted to $10 \mathrm{ml}$ to obtain the concentrations of 40,60 and 80 $\mu \mathrm{g} / \mathrm{ml}$. This procedure was repeated in the subsequent days.

\section{RESULTS AND DISCUSSION}

An objective of this study was to develop an improved simple, selective, accurate, reproducible and sensitive spectrophotometric assay method for Evogliptin tartarate in bulk and pharmaceutical formulation. Evogliptin tartarate is very soluble in water and dilute methanol while freely soluble in organic solvents like ethanol, chloroform and ethyl acetate. During the development phase, deionized water was used as the diluent resulted in preferable outcome in UV analysis showing $267 \mathrm{~nm}$ as wavelength of maximum absorption $\left(\lambda_{\max }\right)$ and none of the component interfered with its quantification.

\section{Validation of developed Method}

The proposed developed method was validated for linearity, sensitivity, selectivity, stability, accuracy and precision as per ICH guidelines, ${ }^{13}$ to prove that the proposed method can be used for the intended purpose.

\section{Linearity}

The linearity of the suggested method was established by evaluating the six samples in triplicate $(n=3)$ in the concentration range of $10-100 \mu \mathrm{g} / \mathrm{mL}$ for Evogliptin tartarate and the amplitude determined was plotted against corresponding concentration to generate the calibration curves (Figure 3) along with regression

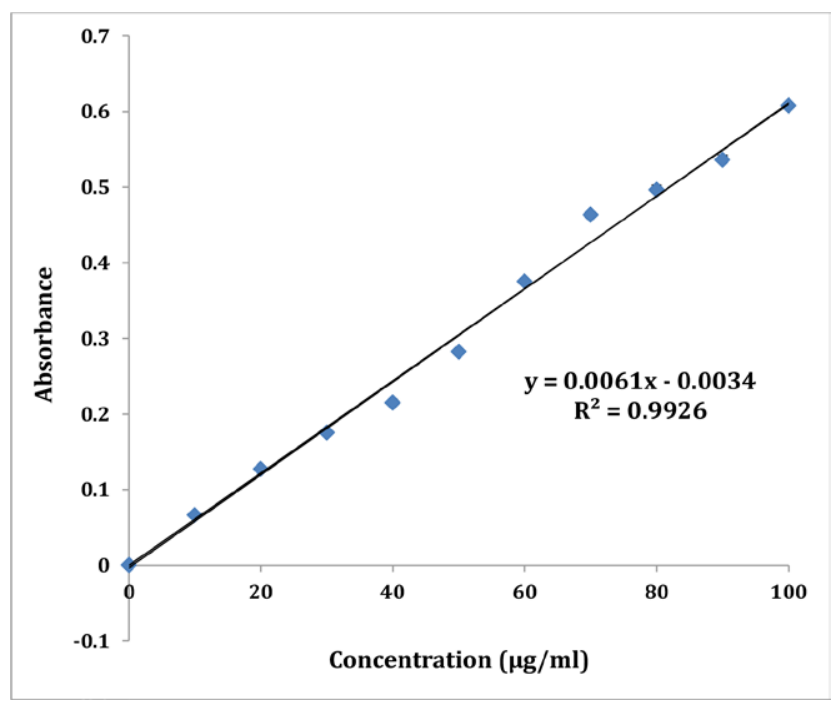

Figure 3: Calibration Curve of Evogliptin Tartarate in deionized water.

Table 1: Regression and validation parameters of Evogliptin tartarate

\begin{tabular}{|c|c|}
\hline Linearity Range in $\boldsymbol{\mu g} / \mathbf{m L}$ & $\mathbf{1 0}$ to $\mathbf{1 0 0} \boldsymbol{\mu g} / \mathbf{m L}$ \\
\hline Regression Equation & $\mathrm{Y}=\mathrm{MX}+\mathrm{C}$ \\
\hline Slope (M) & 0.0061 \\
\hline SD of slop & 0.002 \\
\hline Intercept (C) & -0.0034 \\
\hline$\%$ RSD & 1.23 \\
\hline Correlation coefficient $\left(R^{2}\right)$ & 0.9926 \\
\hline LOD in $\mu \mathrm{g} / \mathrm{mL}$ & $1.08 \mu \mathrm{g} / \mathrm{mL}$ \\
\hline LOQ in $\mu \mathrm{g} / \mathrm{mL}$ & $3.27 \mu \mathrm{g} / \mathrm{mL}$ \\
\hline
\end{tabular}

Each value is average of Three determinations $(n=3)$ 


\begin{tabular}{|c|c|c|c|c|c|c|c|c|}
\hline \multirow{2}{*}{$\begin{array}{l}\text { Conc. } \\
(\mu \mathrm{g} / \mathrm{ml})\end{array}$} & \multicolumn{4}{|c|}{ Intra-day Precision $(n=3)$} & \multicolumn{4}{|c|}{ Inter-day Precision $(n=9)$} \\
\hline & $\begin{array}{c}\text { Absorbance } \\
\text { Measured (Mean + SD) }\end{array}$ & $\begin{array}{l}\text { RSD } \\
(\%)\end{array}$ & $\begin{array}{l}\text { Conc. } \\
\text { Found (\%) }\end{array}$ & $\%$ RE & $\begin{array}{c}\text { Absorbance } \\
\text { Measured (Mean + SD) }\end{array}$ & $\begin{array}{l}\text { RSD } \\
\text { (\%) }\end{array}$ & $\begin{array}{l}\text { Conc. } \\
\text { Found (\%) }\end{array}$ & $\%$ RE \\
\hline 40 & $0.241+0.002$ & .829 & 98.77 & -1.23 & $0.236+0.001$ & .423 & 96.72 & -3.28 \\
\hline 60 & $0.365+0.001$ & .274 & 99.72 & -0.28 & $0.359+0.002$ & .557 & 98.08 & -1.92 \\
\hline 80 & $0.486+0.003$ & .617 & 99.59 & -0.41 & $0.479+0.004$ & .835 & 98.15 & -1.85 \\
\hline
\end{tabular}

Each value is average of determinations

Table 3: Short term stability for three different concentrations of Evogliptin $(n=3)$

\begin{tabular}{|c|c|c|c|}
\hline $\begin{array}{c}\text { Conc. } \\
\text { declared } \\
(\boldsymbol{\mu g} / \mathrm{ml})\end{array}$ & $\begin{array}{c}\text { Conc. found } \\
(\boldsymbol{\mu g} / \mathrm{ml}) \\
(\mathrm{Mean}+\mathrm{SD})\end{array}$ & RSD (\%) & $\begin{array}{c}\text { Average } \\
\text { potency } \\
(\%)\end{array}$ \\
\hline 40 & $39.84+0.051$ & 0.128 & 99.60 \\
\hline 60 & $58.95+0.014$ & 0.023 & 98.25 \\
\hline 80 & $79.08+0.076$ & 0.096 & 98.85 \\
\hline
\end{tabular}

Each value is average of three determinations $(n=3)$

\begin{tabular}{|c|c|c|c|c|}
\multicolumn{5}{|c|}{$\begin{array}{c}\text { Table 5: Determination of Evogliptin Tartarate in } \\
\text { Pharmaceutical preparation using proposed } \\
\text { spectrophotometric methods. }\end{array}$} \\
\hline Batch & $\begin{array}{c}\text { Label claim } \\
\text { (mg) }\end{array}$ & $\begin{array}{c}\text { Amount found } \\
\text { (mg) } \\
\text { (Mean+ SD) }\end{array}$ & $\begin{array}{c}\text { \% } \\
\text { Recovery }\end{array}$ & $\begin{array}{c}\text { RSD } \\
(\%)\end{array}$ \\
\hline Batch A & $5 \mathrm{mg} /$ tablet & $4.903+0.008$ & 98.0 & 0.163 \\
\hline Batch B & $5 \mathrm{mg} /$ tablet & $4.927+0.005$ & 98.4 & 0.101 \\
\hline Batch C & $5 \mathrm{mg} /$ tablet & $4.951+0.006$ & 99.0 & 0.121 \\
\hline
\end{tabular}

Each value is average of three determinations $(n=3)$

\begin{tabular}{|c|c|c|c|c|c|}
\hline \multicolumn{5}{|c|}{ Table 4: Recovery studies for three different concentration of Evogliptin (n=3). } \\
\hline \multirow{2}{*}{ Drug } & $\begin{array}{c}\text { Label } \\
\text { claim }\end{array}$ & Conc. $(\boldsymbol{\mu g} / \mathbf{m L})$ & Recovery level (\%) & $\begin{array}{c}\text { \% Recovery Estimated } \\
\text { (Mean } \pm \text { SD) }\end{array}$ & $\%$ RSD \\
\hline \multirow{3}{*}{ Std. Evogliptin Tartarate } & $5 \mathrm{mg} /$ tablet & 90 & 80 & $99.2 \pm 0.345$ & 0.347 \\
\cline { 3 - 6 } & & 100 & 100 & $99.6 \pm 0.546$ & 0.548 \\
\cline { 3 - 6 } & & 110 & 120 & $99.5 \pm 0.648$ & 0.650 \\
\hline
\end{tabular}

Each value is average of three determinations $(n=3)$

equations. Table 1 , showed results of regression equations with a correlation of coefficient $\left(R^{2}\right)$ greater than 0.992 , proposed that, the analytical methods showed good linearity. Further, the standard deviation of a slope, intercept and residuals were found to be low, confirming the good linearity of the methods.

\section{Sensitivity}

Limit of detection and limit of quantification were calculated to confirm the sensitivity of the method. LOD was determined by multiplying 3.3 with the ratio of the standard deviation of intercept to the slope of the calibration curve. LOQ was determined by multiplying 10 with the ratio of the standard deviation of intercept to the slope of the calibration curve. The LOD and LOQ for Evogliptin Tartarate were observed to be $1.08 \mu \mathrm{g} / \mathrm{mL}$ and $3.27 \mu \mathrm{g} / \mathrm{mL}$ respectively indicated the good sensitivity of the proposed methods.

\section{Precision and Accuracy}

Intra-day and inter-day accuracy and precision were determined by evaluating Evogliptin Tartarate at three different concentration (40,60 and 80) covering the entire calibration range. For intra-day, all these solutions were analyzed by proposed methods on the same day in triplicate $(n=3)$. For inter-day, same solutions were analyzed on three successive days in triplicate $(n=9)$. The precision was expressed as \%RSD (Table 2) and was found to less than $2 \%$, indicating good precision of the procedures. Accuracy was expressed as the percentage relative error $(\% \mathrm{RE})$. The low $\% \mathrm{RE}$ indicated the accuracy of the suggested procedures.

\section{Stability of solutions}

Standard solution were prepared and analyzed spectrophotometrically at initial and after $24 \mathrm{hr}$ (shortterm) to check the stability. The $\%$ RSD for peak areas was determined (Table 3) and found to be less than 2.0 $\%$ which shows that stability of the solution.

\section{Recovery studies}

Recovery studies were executed at three diverse levels $(80 \%, 100 \%$ and $120 \%)$ to confirm the specificity and accuracy of the anticipated approaches by the standard addition method. To the previously analyzed formulation consisting of $50 \mu \mathrm{g} / \mathrm{mL}$ of Evogliptin Tartarate and 40, 50 and $60 \mu \mathrm{g} / \mathrm{mL}$ of Evogliptin were added separately. All these solutions were analyzed by proposed methods and peak amplitudes were determined. The concentration of the added amount of Evogliptin was calculated 
using the regression equation and subtraction of initial formulation concentration. The good recovery of Evogliptin from the formulation with low \% RSD (Table 4) confirmed the specificity and accuracy of the suggested approaches.

\section{Application of proposed methods Application to a marketed pharmaceutical preparation}

Proposed spectroscopic procedures were utilized for quantification of Evogliptin Tartarate from three different batches of market formulation "Valera" (label claims $5 \mathrm{mg}$ Evogliptin Tartarate). The results were tabulated in Table 5 . The recovery results were inconsistent with the labeled amount with \% RSD $<2 \%$, indicating the suitability of the suggested procedures for regular quality control of Evogliptin Tartarate in pharmaceutical preparations.

\section{CONCLUSION}

Developed selective, accurate, precise, sensitive and robust UV spectroscopic method for the first time, for concurrent quantification of Evogliptin Tartarate in pure form and pharmaceutical tablets formulations with low cost. A good recovery of method showed that there is no interference of excipients used in the formulations at analyte. Water has been used as a solvent, making this method economic and eco-friendly. The outcome of the validation study showed that the developed UV spectrophotometric method for Evogliptin Tartarate will serve as a standard protocol for routine analysis of Evogliptin tartarate in bulks, Pharmaceutical formulations and would be of great help to Pharmaceutical industries in the future.

\section{ACKNOWLEDGEMENT}

The authors are thankful to Alkem Laboratories Limited, Mumbai, India for providing the reference standard and the Principal, Government College of Pharmacy, Ratnagiri, for providing necessary facilities for research.

\section{CONFLICT OF INTEREST}

The authors declare no conflict of interest.

\section{ABBREVIATIONS}

API: Active Pharmaceutical Ingredients; UV: Ultra Violet Spectroscopy; DPP: dipeptidyl peptidase; conc.: Concentration; std.: Standard; RSD: Relative Standard Deviation; SD: Standard Deviation; RPM: Rotation per minute; $\mathrm{ml} / \mathrm{mL}$ : Mili Liter; lit.: Liter; $\mu \mathrm{l}$ : Micro Liter; $\mu \mathrm{g}$ : Micro Gram; mg: Mili Gram; Gm: Gram; Kg: Kilo Gram; Min: Minute; Hr.: Hour; ${ }^{\circ} \mathrm{C}$ : Degree centigrade; \%: Percentage; v/v: Volume by volume; $\lambda_{\text {max: }}$ Wavelength maxima; LOD: Limit of Detection; LOQ: Limit of Quantitation.

\section{REFERENCES}

1. American Diabetes Association. Diagnosis and classification of Diabetes mellitus, Diabetes Care. 2014;37(1):S81-90.

2. Garber AJ, Abrahamson MJ, Barzilay JI, et al. AACE comprehensive diabetes management algorithm. Endocr Pract. 2013;19(2):327-36.

3. Inzucchi SE, Bergenstal RM, Buse JB, Diamant M, Ferrannini E, et al. Management of hyperglycemia in type 2 diabetes, 2015: A patient-centered approach: Update to a position statement of the American Diabetes Association and the European Association for the Study of Diabetes. Diabetes Care. 2015;38(1):140-9.

4. Drucker DJ, Nauck MA. The incretin system: Glucagon-like peptide-1 receptor agonists and dipeptidyl peptidase-4 inhibitors in type 2 diabetes. Lancet. 2006;368(9548):1696-705.

5. Rodbard HW, Jellinger PS, Davidson JA. Statement by an American Association of Clinical Endocrinologists/American College of Endocrinology consensus panel on type 2 Diabetes mellitus: an algorithm for glycemic control. Endocr Pract. 2009;15(6):540-59.

6. Kim TE, Lim KS, Park MK, Yoon SH, Cho JY, Shin SG, et al. Evaluation of the pharmacokinetics, food effect, pharmacodynamics and tolerability of DA-1229, a dipeptidyl peptidase IV inhibitor, in healthy volunteers: first-inhuman study. Clin Ther. 2012;34(9):1986-98.

7. Gu N, Park MK, Kim TE, Lim KS, Yoon SH, et al. Multiple-dose pharmacokinetics and pharmacodynamics of evogliptin (DA-1229), a novel dipeptidyl peptidase IV inhibitor, in healthy volunteers. Drug Des Devel Ther. 2014;8:1709-21.

8. Jung $\mathrm{CH}$, Park $\mathrm{CY}$, Ahn KJ, Kim NH, Jang HC, Lee MK, et al. A randomized, double-blind, placebo-controlled, phase II clinical trial to investigate the efficacy and safety of oral DA-1229 in patients with type 2 Diabetes mellitus who have inadequate glycaemic control with diet and exercise. Diabetes Metab Res Rev. 2015;31(3):295-306.

9. Trailokya A, Ajmani AK, Agrawal A, Prasad BLN, Basu I, Shembalkar J, et al. Efficacy and safety of evogliptin versus sitagliptin as an add-on therapy in Indian patients with type 2 Diabetes mellitus inadequately controlled with metformin: A 24-week randomized, double-blind, non-inferiority, Evolution India study. Diabetes Res Clin Pr. 2019;157:107860.

10. Rhee SJ, Seung HL, Yoon SH, Cho JY, Jang IJ, et al. Pharmacokinetics of the Evogliptin/metformin extended-release $(5 / 1,000 \mathrm{mg})$ fixed-dose combination formulation compared to the corresponding loose combination and food effect in healthy subjects. Drug Des Devel Ther. 2016;10:1411-8.

11. Cho K. Bioanalytical validation for the determination of evogliptin and its metabolites $\mathrm{m} 7 / \mathrm{m} 8$ in human plasma by liquid chromatography-tandem mass spectrometry. Proceedings of the $12^{\text {th }}$ International society for the study of Xenobiotics Meeting; Oregon Convention Center, Portland, Oregon, United States of America. 2019;28-31.

12. Jeong HU, Kim JH, Lee DY, Shim HJ, Lee HS. In-vitro Metabolic Pathways of the New Anti-Diabetic Drug Evogliptin in Human Liver Preparations. Molecules. 2015;20(12):21802-15.

13. Joan CK, Chokkareddy R, Nicholas R, Redhi GG. A novel electrochemical sensor for selective determination of theophylline in pharmaceutical formulations, Journal of the Taiwan Institute of Chemical Engineers. 2020; 111:228-238.

14. Chokkareddy R, Bhajanthri NK, Redhi GG, and Redhi DG. Ultra-Sensitive Electrochemical Sensor for the Determination of Pyrazinamide, Current Analytical Chemistry. 2018; 14(4): 391-398.

15. European Medicines Agency. International Conference on Harmonization (ICH). Validation of Analytical procedures: Text and Methodology (Q2R1); Geneva: IFPMA. 2006;1-15. 


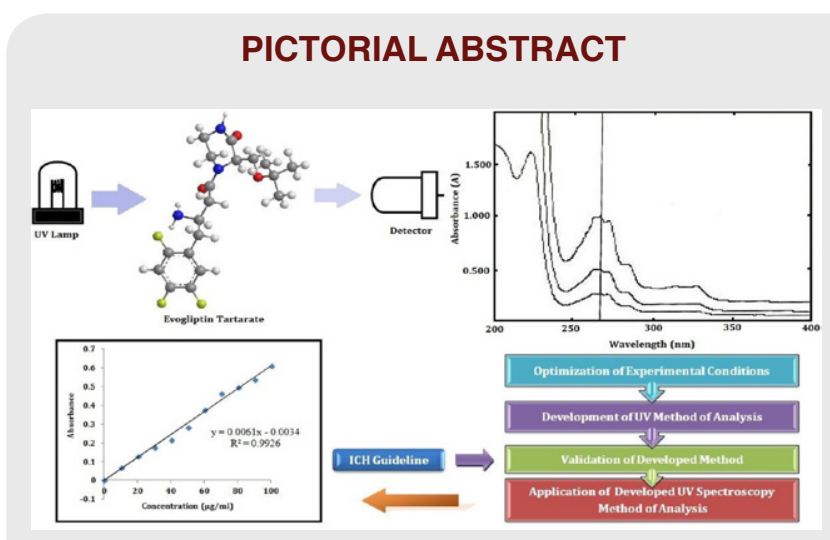

\section{SUMMARY}

Developed UV-spectrophotometric method for the analysis of Evogliptin tartarate and validated as per $\mathrm{ICH}$ Q2 (R1) guidelines

\section{About Authors}

Dr. Yogesh P. Agrawal, M.Pharm, Ph.D (Pharmaceutical Chemistry) currently is working as Assistant Professor, Government College of Pharmacy, Ratnagiri. Competent professional with over 10 years of experience in Teaching, Research and Training on handling of Analytical Instruments

Cite this article: Agrawal YP, Agrawal MY, Jadhav SB, Shinde RJ. Development and Validation of Novel UV Spectrophotometric Method for the Determination of Evogliptin Tartarate in Pharmaceutical Dosage Form. Indian $\mathrm{J}$ of Pharmaceutical Education and Research. 2020;54(4):1174-9. 